\title{
Cross-talk between NO and HMGB1 in lymphocytic thyroiditis and papillary thyroid cancer
}

\author{
STEFANIA MARDENTE ${ }^{1}$, ALESSANDRA ZICARI $^{1}$, FABRIZIO CONSORTI $^{2}$, EMANUELA MARI $^{1}$, \\ MAURA DI VITO ${ }^{1}$, MARTINA LEOPIZZI ${ }^{1}$, CARLO DELLA ROCCA ${ }^{1}$ and ALFREDO ANTONACI ${ }^{2}$
}

\author{
Departments of ${ }^{1}$ Experimental Medicine and ${ }^{2}$ Surgery and Applied Surgical Technologies, \\ University Sapienza, Viale Regina Elena 324, 00161 Rome, Italy
}

Received May 20, 2010; Accepted July 6, 2010

DOI: $10.3892 /$ or_00001005

\begin{abstract}
The controversy on whether or not inflammatory infiltrates in chronic lymphocytic thyroiditis predispose to cancer, has now merged into a debate over the role of the inflammatory infiltrates. The question is how and why some cells become transformed and what factors allow them to spread and in some cases become invasive. Here, we show that the amount of inflammatory mediators such as nitric oxide (NO) and high mobility group Box 1 protein (HMGB1) produced in thyroiditis microenvironment increases in tumors and could be involved in the cellular transformation process. NO and HMGB1 are known to attract macrophages that would promote angiogenesis, matrix remodelling and suppression of an efficient immune response. Inflammatory infiltrates could increase the risk of papillary cancer in patients with autoimmune lymphocytic thyroiditis. Cytokines and soluble inflammatory mediators involved in cancer-related inflammation are not only a target for innovative diagnostic and therapeutic strategies but they also represent a future challenge for oncologists.
\end{abstract}

\section{Introduction}

The frequent transition from chronic thyroiditis to papillary cancer has been our interest for several years (1). It is known that submicroscopic foci of papillary carcinoma exist in lymphocytic thyroiditis although their behaviour is not invasive. On the other hand, some microscopic papillary carcinomas show a metastatic phenotype. In this setting autoimmune thyroiditis and papillary cancer have provided a useful model with which to examine interactions between cancer and the immune system (2).

Correspondence to: Dr Stefania Mardente, Department of Experimental Medicine, University Sapienza, Viale Regina Elena 324, 00161 Rome, Italy

E-mail: stefania.mardente@uniroma1.it

Key words: nitric oxide, high mobility group box 1, thyroiditis, papillary cancer
We have recently demonstrated (3) that peripheral lymphocytes (type Tc1 and Tc2) infiltrate thyroids in autoimmune thyroiditis and in most papillary carcinomas. Whether these infiltrates occur before or after thyroiditis is not yet clear. Direct cytotoxicity, secretion of cytokines and high concentrations of NO, suppress the 'protective' immune process and promote dangerous mutations that could lead to cancer (4). As well as the above immune mechanisms, a central role has been given to the de-repression of tumor suppressor genes or oncogenes or to transduction or transcription factors (5). NO plays a role in inflammation-associated carcinogenesis by direct modification of DNA and inactivation of DNA repair enzymes (6). NO is synthesized by three synthase isoforms (NOS), each produced as a separate gene product, eNOS and nNOS are constitutively expressed and produce low levels of NO while iNOS is expressed only after induction by cytokines or other inflammatory products and produces high amounts of NO $(7,8)$. A microenvironment rich of NO and HMGB1 has been demonstrated in colon cancer and could contribute to cellular transformation (9).

HMGB1 is a nuclear protein linked to DNA that helps the binding of proteins like p53 at their chromatin sites (10). HMGB1 is ubiquitously expressed in vertebrate nuclei and has been implicated in a variety of biologically important processes, including transcription, DNA repair, differentiation, development and extracellular signalling. In certain cell types this protein has been observed at the cell surface where it has been reported to contribute to cellular migration and tumor invasion. HMGB1 is passively secreted by necrotic cells thereby, recalling inflammatory cells. By contrast, in apoptotic cell death, HMGB1 is sequestered in the nucleus, even when the integrity of the plasma membrane is lost. In the light of this evidence HMGB1 can be regarded as a critical stimulus of inflammation at the site of cell injury and is capable of affecting the host inflammatory response. In inflammatory sites, monocytes and macrophages secrete HMGB1 without dying. This happens through active transportation from the nucleus to cytoplasmic organelles, where it is acetylated and then secreted in the extracellular spaces. Extracellular HMGB1 activates various receptors including RAGE, a member of the Ig superfamily and TLR 2 and 4. This induces the production of several cytokines and costimulatory molecules even in presence of damaged cells, not necessarily in inflammatory sites. 
Table I. Patient characteristics.

\begin{tabular}{|c|c|c|c|c|c|c|}
\hline \multirow[b]{2}{*}{ No. of patients } & \multirow[b]{2}{*}{ Cancer } & \multicolumn{3}{|c|}{ Thyroiditis only } & \multirow[b]{2}{*}{ Multinodular goiters } & \multirow[b]{2}{*}{ Total } \\
\hline & & & Grade 2 & Grade 3 & & \\
\hline Female/Male & $42 / 18$ & $35 / 5$ & 24 & 17 & $7 / 3$ & $\begin{array}{c}84 / 26 \\
110\end{array}$ \\
\hline Median age & 58 & & & 52 & 55 & \\
\hline pT1NxMx & $8 / 7$ & & & & & 15 \\
\hline pT2NxMx & $18 / 4$ & & & & & 22 \\
\hline pT3NxMx & $16 / 7$ & & & & & 23 \\
\hline
\end{tabular}

HMGB1 is an important mediator of late inflammation and can cause inappropriate induction of proinflammatory genes in tumor and stromal cells. Among these, NF- $\kappa \mathrm{B}$ is abnormally expressed in many malignancies and extensively investigated because of its role in tumorigenesis (11). NF-кB has been identified as a potential molecular bridge between inflammation and cancer (12). Our interest is the role played by the microenvironment in the frequent transition from a chronic inflammation represented by lymphocytic thyroiditis to papillary cancer.

\section{Materials and methods}

Sample collection and culture of cells. This study included 110 patients (Table I) who underwent thyroidectomy for a suspected lymphocytic thyroiditis or a preoperative diagnosis of thyroid cancer, by fine needle aspiration cytology (FNA). Patients with Graves disease were excluded from the study.

The 40 patients with lymphocytic thyroiditis had elevated antiperoxydase titer (anti-TPO $>150 \mathrm{U} / \mathrm{ml}$ ). Thyroiditis was graded on morphological features of cytological material according with Bhatia et al (13), subsequently confirmed by histology. Briefly, there were 4 grades: grade 0 in which lymphoid cells were absent, grade 1 with few lymphoid cells infiltrating the follicles, grade 2 with moderate lymphocytic infiltration, presence of Hurtle cells and anisonucleosis and grade 3 with germinal centre formation and severe thyreocyte depletion. On examination, while performing FNAC, 35 of this group of patients had diffuse goiter and 5 had nodular goiter. All patients with thyroiditis experienced hypothyroid symptoms. Papillary cancer was diagnosed in 60 patients. This group of patients had TPO $\leq 90 \mathrm{U} / \mathrm{ml}$. Standard histology and where required, galectin 3 and HBME1 expression, confirmed the diagnosis (14) and allowed us to exclude from this study all those patients who had both thyroiditis and papillary cancer. Ten patients with multinodular goiter and TPO $\leq 90 \mathrm{U} / \mathrm{ml}$ were included in the study as negative controls. All patients were informed and agreed to participate in our study, in accordance with our institution ethical standards.

Small fragments of the nodules were collected from fresh samples and thyreocytes were obtained by cutting and several passages through fine meshes and needles. Cells were cultured for $24 \mathrm{~h}$ in RPMI at $37^{\circ} \mathrm{C}, 5 \% \mathrm{CO}_{2}$. Where required, $40 \mathrm{nM}$ HMGB1 (Sigma) or $2 \mathrm{mM}$ natrium nitroprusside (Sigma) was added to the cultures. Natrium nitroprusside was used as nitric oxide donor. Cell viability, checked by Trypan blue exclusion test, was always between 95-98\%. Cell purity was assessed randomly by spotting $200 \mu 1$ of cell suspension on a glass slide and staining with May Grunwald Giemsa. Cell populations were mainly made up of thyreocytes $(80 \%)$. Controls (CTRL) were obtained from multinodular goiters and where possible from controlateral lobes with negative hystology for both thyroiditis and cancer.

Whole cell lysates from cancer patients (15 of the pT2NxMx group and 10 of the pT3NxMx group) were selected for the NF- $\mathrm{NB}$ expression.

At the end of incubation time, supernatants were collected for the nitrite assay, while cell pellets were lysed for Western blot analysis.

Cell lines. The Jurkat cell line is a well established human leukemia $\mathrm{T}$ cell line used as a positive control for the NF-кB Western blot analysis.

Nitrite assay. To assess the amount of NO produced by the cells the concentrations of the stable end nitrite products in the culture supernatants were measured by the Griess reaction microassay as previously described (15). In brief, an equal volume of the Griess reagent was added to $100-\mu 1$ aliquots of culture medium and incubated for $10 \mathrm{~min}$ at room temperature. Optical densities were measured at $550 \mathrm{~nm}$ by a microplate photometer (Bio-Rad 550 microplate reader, Hercules CA). A standard curve was made by serial dilutions $(0.5-50 \mu \mathrm{M})$ of $\mathrm{NaNO}_{3}$. Reagent blanks were prepared for each assay by adding $100 \mu \mathrm{l}$ of culture medium to the Griess reagent. A correction of the absorbance was made for each sample by subtracting the readings of the blank to the readings of the sample. Each assay was performed in triplicate. The minimum detectable amount of nitrites was $5 \mu \mathrm{M}$. Intra- and interassay coefficients of variation were $<10 \%$. Protein concentration of the cell culture was determined using a Bradford protein assay (Bio-Rad laboratories) with bovine serum albumine (BSASigma Aldrich, St. Louis, MO) as standard. 
Western blot analysis. Whole cell lysates, were separated on $7.5 \%$ SDS-polyacrylamide electroforesis gel for iNOS analysis on $15 \%$ for HMGB1 and on $10 \%$ for NF- $\mathrm{NB}$.

Samples were heat-denaturated for $5 \mathrm{~min}$, loaded on standard Tris- $\mathrm{HCl}$ polyacrylamide gel and run on ice at $40 \mathrm{~V}$ for the stacking gel and $80 \mathrm{~V}$ for the running gel. Proteins were transferred to a PVDF membrane (Bio-Rad, Hercules), previously activated in $100 \%$ methanol for $15 \mathrm{sec}$ and then washed in blotting buffer for $15 \mathrm{sec}$. The membrane was blocked in TBS-T and 5\% albumin for $1 \mathrm{~h}$, probed overnight at $4^{\circ} \mathrm{C}$ with a specific primary antibody. The proteins were detected at $4^{\circ} \mathrm{C}$ by the specific antibody (monoclonal AntiiNOS by Santa Cruz Biotechnology, Santa Cruz, CA); monoclonal anti-HMGB1 by Sigma) and polyclonal rabbit anti-NFkB p50 and p65 (Upstate, Lake Placid, NY). One hour after adding the antibodies, the membrane was washed with TBS-T and incubated with anti-mouse IgG peroxidaseconjugated secondary antibodies (1:10000 Sigma) for $1 \mathrm{~h}$ at room temperature. The signal was detected by autoradiography (Kodak Biomax Light Film Sigma-Aldrich) using Chemiluminescent Peroxidase Substrate kit (SigmaAldrich), then quantified by densitometric analysis using a software (Quantity-One, Bio-Rad).

Immunohistochemistry and result evaluation. Sections $(3 \mu 1)$ of all excised samples were used for standard histology. Sections $(5 \mu \mathrm{m})$ from the same paraffin-embedded blocks were rehydrated and immunolabelled with anti-iNOS monoclonal antibody (RD system). Immuoreactivity was independently assessed by two of the authors (Leopizzi and Della Rocca), the results were compared and an agreement was reached on conflicting evaluation. The intensity of cytoplasmic staining was graded from 0 to 3 as follows: grade 0 , absence of staining; grade 1 , faint staining (requiring high power assessment); grade 2, moderate staining (easily appreciated at low power); and grade 3 , intense staining. The distribution of positive cells was also graded as follows: focal staining in $<10 \%$ of cells; widespread staining in up to $50 \%$ of cells and diffuse staining in $>50 \%$ of cells.

Statistical analysis. All determinations were carried out three times. Data are expressed as means \pm SD. Data were analyzed by Student's t-test. $\mathrm{p}<0.05$ was considered statistically significant.

\section{Results}

NO release in thyroiditis and papillary cancer. Fig. 1 demonstrates that NO is released in supernatants from controls, thyroiditis and cancer cell cultures treated or not with HMGB1. NO release was maximum in cancer samples treated with HMGB1 and followed the same trend in thyroiditis samples when compared with controls obtained from the healthy lobes from the same patient. Immunohistochemistry (Fig. 2), performed in samples from all patients showed that iNOS is not constitutively expressed in thyroid, its expression becomes evident in thyroiditis samples and is higher in tumors. Samples with micro-macro follicular hyperplasia and healthy thyroid tissues were graded 0 or 1 , while the thyroiditis samples were all graded 2 , in terms of both intensity of staining and

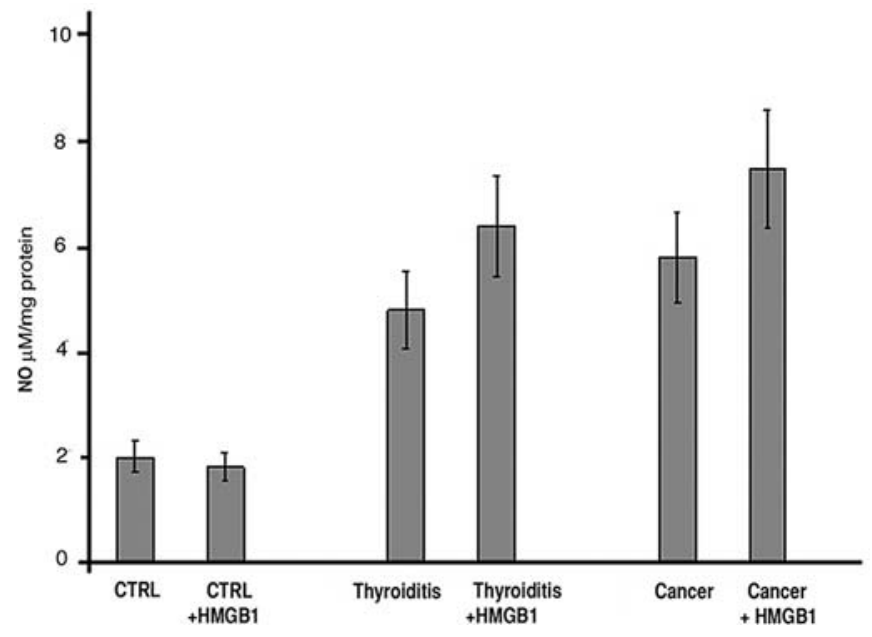

Figure 1. NO released in supernatants from 24-h cultures of thyreocytes from controls, thyroiditis and papillary cancer. Each assay was performed in triplicate. Data are expressed as NO $\mu \mathrm{M}$ per $\mu \mathrm{g}$ of protein. In controls versus cancer $\mathrm{p}<0.001$; thyroiditis versus cancer $\mathrm{p}<0.05$.

percentage of positive cells. The tumor samples were all positive, the intensity of staining was 3 for 9 cancer samples and 2 for 1 sample while the distribution of positive cells was 3 (diffuse) in all samples.

Expression of HMGBland iNOS in thyroiditis and papillary cancer. Fig. 3 shows the expression of HMGB1 in lysates from thyreocytes in thyroiditis and papillary cancer cultures with and without treatment with NP. HMGB1 expression is very low in healthy thyroids, it increases in thyroiditis and it reaches the highest levels in papillary cancer. HMGB1 is detectable in two isoforms of $28 \mathrm{kDa}$ and the acetylated, active form of $30 \mathrm{kDa}$. Addition of nitric acid donor (NP) to the cultures decreases the expression of HMGB 1 in both thyroiditis and cancer. The decrease is more evident in thyroiditis than in cancer.

Fig. 4 shows the expression of iNOS in cancer and thyroiditis cells treated or not with HMGB1. A remarkable increase of 4-fold was induced by exogenous HMGB1 in thyroiditis compared with the controls.

$H M G B 1$ activates $N F-\kappa B$. In order to assess whether HMGB1 was able to activate NF- $\kappa B$ in papillary cancer cells we cultured thyreocytes from 10 goiters (CTRL) and from 6 papillary tumors (all from the pT3NxMx group) in the presence of $40 \mathrm{ng} / \mathrm{ml}$ of HMGB1. Fig. 5 shows that p50 and p65 NF- $\mathrm{KB}$ are not detectable in the controls (CTRL) while they are both expressed in cancer. The addition of HMGB1, did not produce any effect in CTRL samples, whereas in cancer cultures increased the expression of both $\mathrm{NF}-\kappa \mathrm{B}$ isoforms. This demonstrates that HMGB1 is able to activate $\mathrm{NF}-\kappa \mathrm{B}$ in tumor cells.

\section{Discussion}

There has traditionally been controversy on whether or not lymphocytic thyroiditis predisposes to or protects from cancer. 

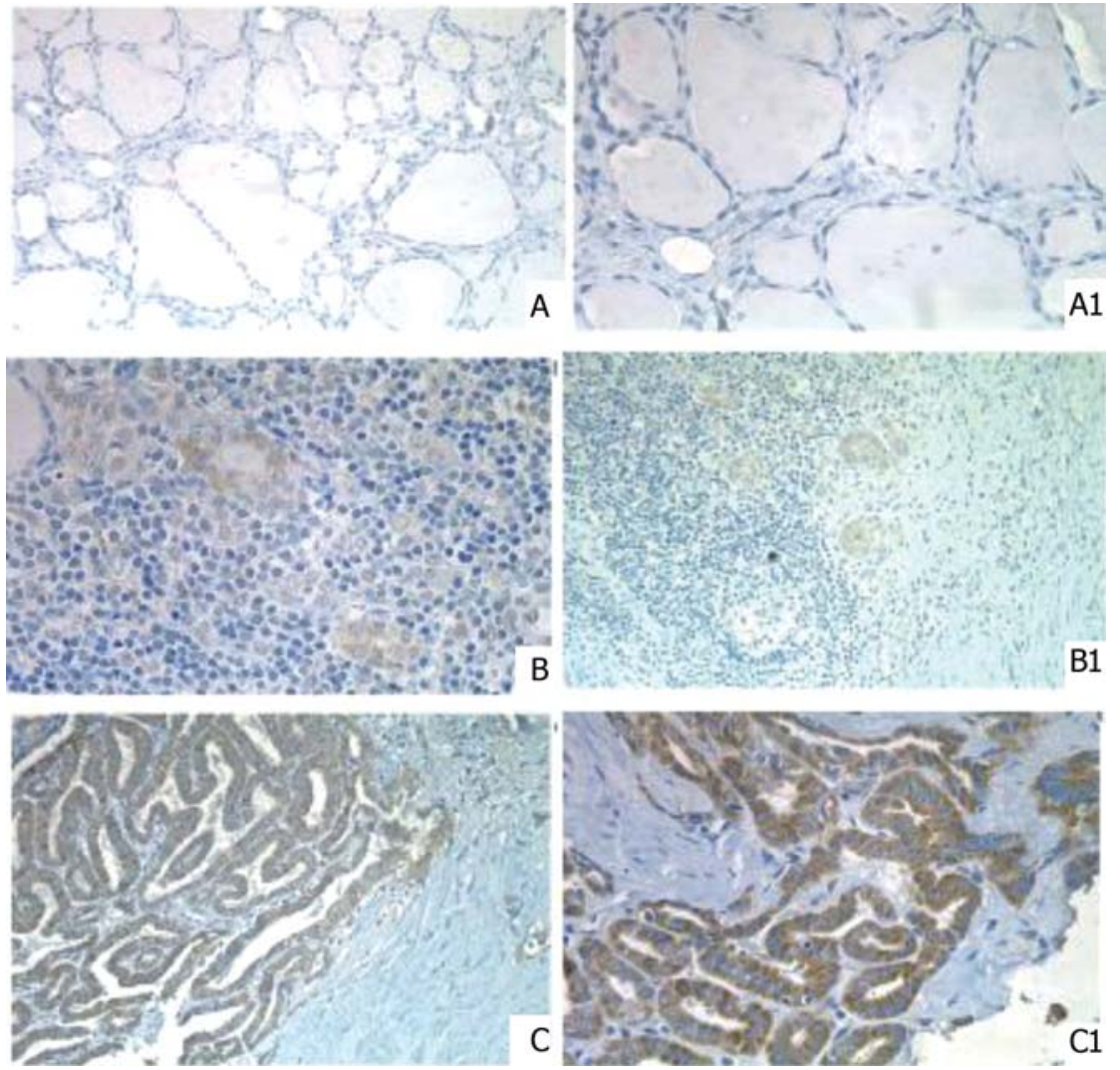

Figure 2. Expression of iNOS in micro-macrofollicular hyperplasia (A and A1; x10 and x40 magnification, respectively), thyroiditis (B and B1) and papillary cancer (C and $\mathrm{C} 1)$. The HRP-conjugated anti-iNOS antibody brown stain is particularly evident in the papillary cancer samples. A representative experiment is shown.

\section{HMGB1}
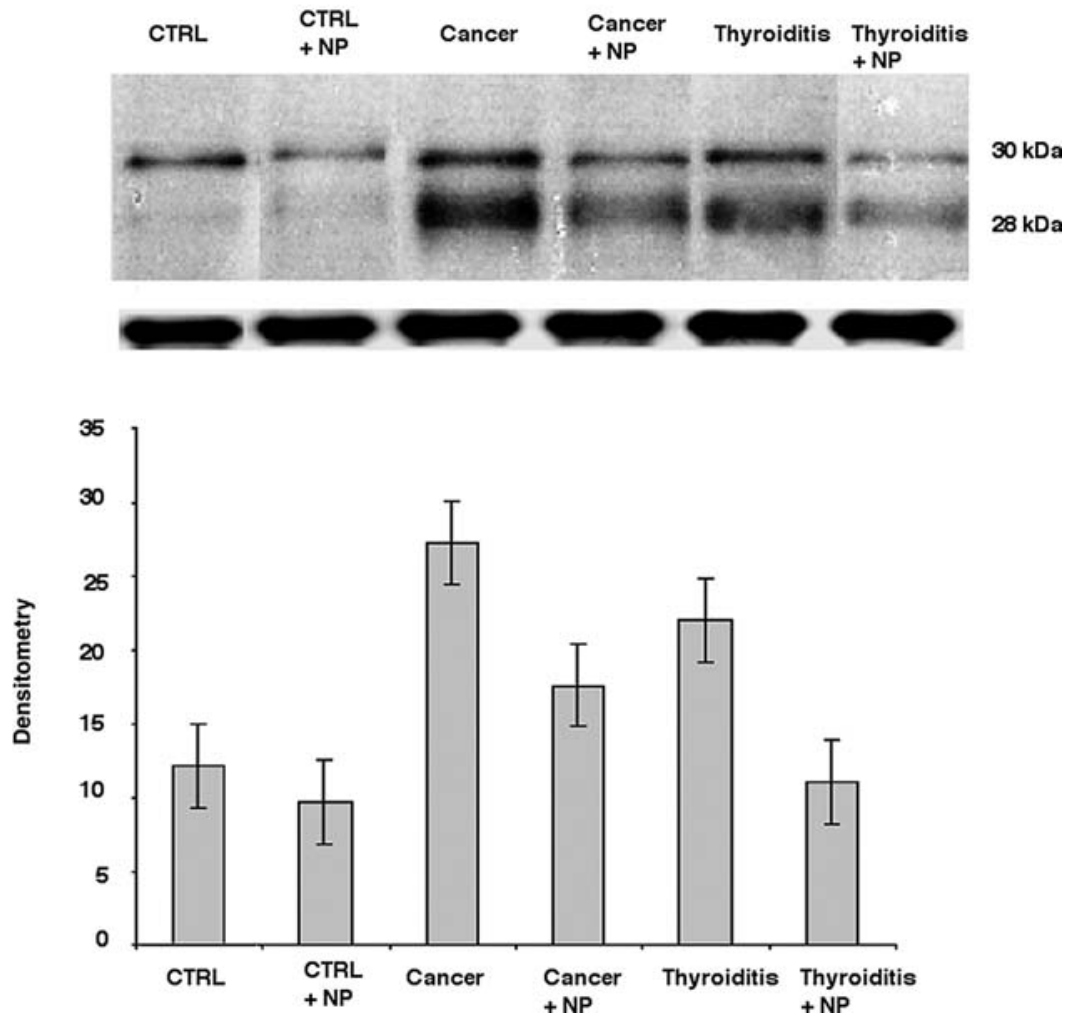

Figure 3. Expression of HMGB1 in cell lysates from controls, thyroiditis and cancer cells cultured with (+NP) and without NP. The HMGB1 acetylated form is the $30-\mathrm{kDa}$ band. Both bands are more intense in cancer cells than in thyroiditis or controls. The addition of NO donor decreases the intensity of the bands. Densitometry was performed in all blots and data are expressed in percentage $( \pm \mathrm{SD})$. A representative experiment is shown. 


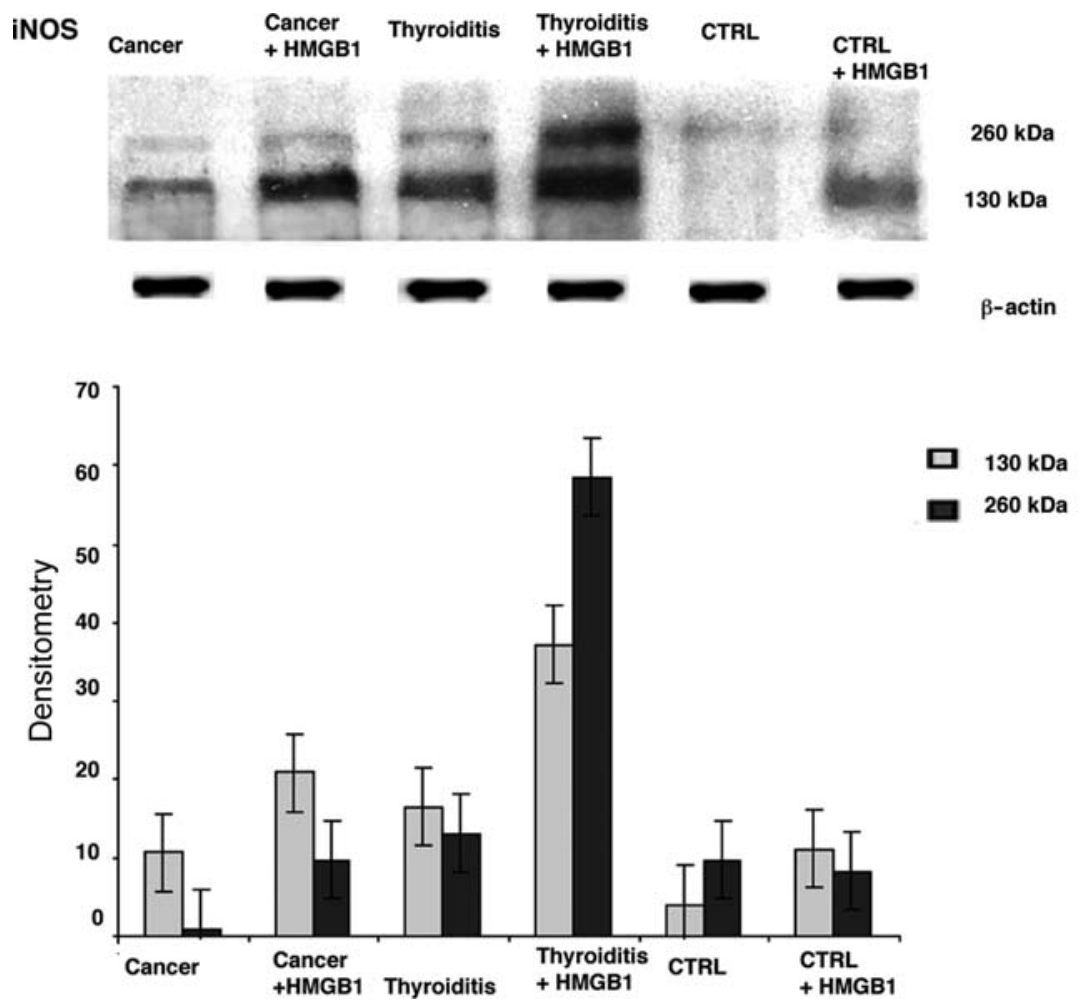

Figure 4. Expression of iNOS in cell lysates from controls, thyroiditis and cancer cells cultured with (+HMGB1) and without HMGB1. iNOS bands of $260 \mathrm{kDa}$ (dimeric, active) and $130 \mathrm{kDa}$ (monomeric, inactive) are more intense in cancer cells treated with HMGB1. Densitometry was performed in all blots and data are expressed in percentage $( \pm \mathrm{SD})$. A representative experiment is shown.
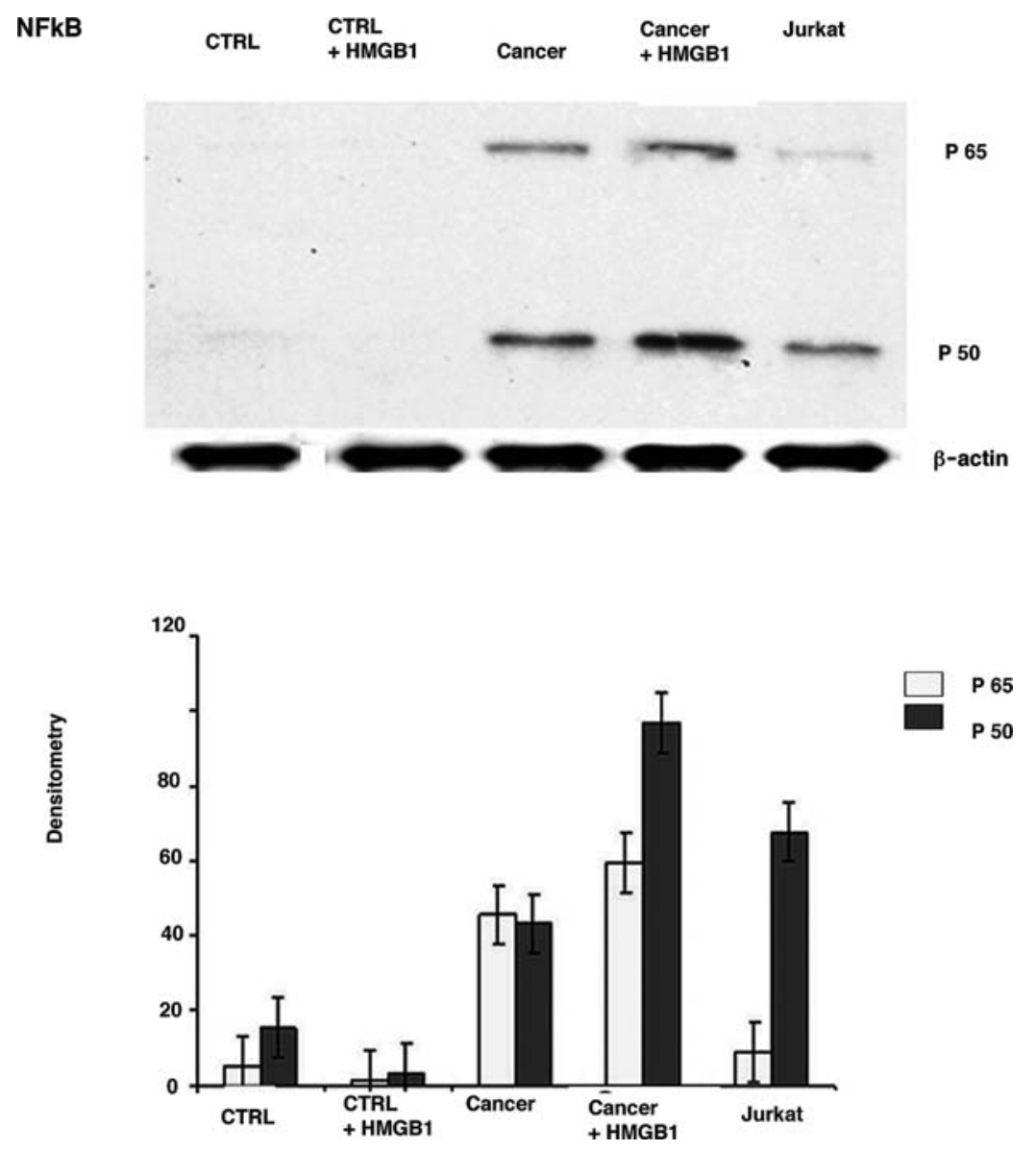

Figure 5. Expression of NF-кB in cell lysates from control and tumor cells cultured in presence of HMGB1 for 24 h. The two isoforms of NF- $\mathrm{BB}$ are evident exclusively in the cancer lanes. The Jurkat cell line was used as a positive control. A representative experiment is shown. Histograms show the densitometry of all blots, data are expressed in percentage $( \pm$ SD). $\beta$-actin expression was used as quantitative control. 
Some clinical studies (16) based on follow-up of patients and statistical data, show that lymphocytic thyroiditis may protect patients from developing papillary tumors, or is associated to a better outcome of the disease (17), while other authors suggest that chronic inflammation may help cellular transformation (18). This controversy has now merged into a new debate over the role of chronic inflammation, which is seen as a cancer risk factor in all tissues. In some studies autoimmune thyroiditis is seen as a premalignant lesion on the grounds that thyroiditis and papillary cancer share many genetic features and mutations in 'dangerous genes' like p53 and BCL2. The question is how and why some cells get transformed and what factors allow them to spread and in some cases become invasive. The above results show that in both pathologies, factors involved in apoptosis and or necrosis are expressed in a manner that is strictly related to the pathology. In other words, NO started to be produced in the thyroiditis microenvironment and then it always increased in the tumours. These results suggest that chronic inflammation infiltrates may contribute to the tumor escape from the immunesurveillance and perhaps drive the tumor transformation process. Other authors have reported that inflammatory mediators such as iNOS and COX-2 have been found overexpressed $(19,20)$ in the microenvironment of lymphocytic thyroiditis and thyroid tumors indicating that both might have a role in underlying processes. We added that the overexpression of iNOS is related to increased NO production and that exogenous NO is able to reduce HMGB1 expression in our experimental model. Other authors (21) demonstrated that the release of large amounts of NO by iNOS can inhibit the induction of COX-2. This may be explained with a differential regulation of these substances, perhaps due to the changing pattern of cytokines and inflammatory molecules during the different phases of inflammation. (22). Moreover, we have shown that HMGB1 is overexpressed in thyroiditis and cancer. Interestingly, exogenous HMGB1 is able to induce iNOS and $\mathrm{NO}$ as well as up-regulation of NF- $\mathrm{NB}$ in cancer cells. Therefore, we can hypothesize that local chronic inflammation in thyroids may disrupt the cellular epigenetic machinery, thereby, contributing indirectly to neoplastic transformation. HMGB1 has been studied recently in many solid cancers as it has an inhibitory effect on the response to cisplatin therapy (23) and it is chemotactic for macrophages. In our previous study we demonstrated that Th1 lymphocytes predominate in autoimmune thyroiditis in both peripheral blood and in thyroid sites while in infiltrates of papillary tumors there is a change of $\mathrm{T}$ lymphocyte subsets into $\mathrm{Th} 2$ that release IL4. IL4 has been shown to be chemotactic for M2 macrophages that promote tumor growth and progression (24) and for this reason they are targets of new immunotherapies still under study.

In conclusion, we have shown that NO is not only released in the thyroiditis microenvironment by inflammatory cells, but its release increases significantly in papillary cancer being probably responsible for the release of HMGB1. HMGB1 in turn, is able to activate NF- $\kappa \mathrm{B}$ in thyreocytes from papillary cancer cultures, thereby maintaining peritumoral inflammation.

\section{Acknoledgements}

The authors would like to thank professor Hugo Bowles for language proofreading and professor G.M. Pontieri for reviewing the manuscript. This study was supported by grant Ateneo 60\% (2004) to professor A. Antonaci.

\section{References}

1. Antonaci A, Consorti F, Mardente S, Natalizi S, Giovannone G and Della Rocca C: Survivin and cyclin D1 are jointly expressed in thyroid papillary carcinoma and microcarcinoma. Oncol Rep 20: 63-67, 2008.

2. Antonaci A, Consorti F, Mardente S and Giovannone G: Clinical and biological relationship between chronic lymphocytic thyroiditis and papillary thyroid carcinoma. Oncol Res 17: 495-503, 2009.

3. Mardente S, Lenti L, Lococo E, Consorti F, Della Rocca C, Romeo S, Misasi R and Antonaci A: Phenotypic and functional characterization of lymphocytes in autoimmune thyroiditis and in papillary carcinoma. Anticancer Res 25: 2483-2488, 2005.

4. Lala PK and Orucevic A: Role of nitric oxide in tumor progression: lessons from experimental tumors. Cancer Metastasis Rev 17: 91-106, 1998.

5. Arif S, Blanes A and Diaz-Cano SJ: Hashimoto's thyroiditis shares features with early papillary thyroid carcinoma. Histopathology 41: 357-362, 2002.

6. Jaiswal M, La Russo NF, Burgart LJ and Gores GJ: Inflammatory cytokines induce DNA damage and inhibit DNA repair in cholangiocarcinoma cells by a nitric oxide-dependent mechanism. Cancer Res 60: 184-190, 2000.

7. Vane JR, Mitchell JA, Appleton I, Tomlinson A, BishopBailey D, Croxtall J and Willoughby DA: Inducible isoforms of cyclooxygenase and nitric-oxide synthase in inflammation. Proc Natl Acad Sci 91: 2046-2050, 1994.

8. Nose F, Ichikawa T, Fujiwara M and Okayasu I: Up-regulation of cyclooxygenase-2 expression in lymphocytic thyroiditis and thyroid tumours: significant correlation with inducible nitric oxide synthase. Am J Clin Pathol 117: $546-551,2002$.

9. Kuniyasu H, Yano S, Sasaki T, Sasahira T, Sone S and Ohmori H: Colon cancer cell-derived high mobility group 1/ amphoterin induces growth inhibition and apoptosis in macrophages. Am J Pathol 166: 751-760, 2005.

10. Anderson UG and Tracey KJ: HMGB1, a pro-inflammatory cytokine of clinical interest: introduction. J Intern Med 255: 318-319, 2008.

11. Pikarsky E, Porat RM, Stein I, Abramovitch R, Amit S, Kasem S, Gutkovich-Pyest E, Urieli-Shoval S, Galun E and Ben-Neriah Y: $\mathrm{NF}-\kappa \mathrm{B}$ functions as a tumor promoter in inflammation-associated cancer. Nature 431: 461-466, 2004.

12. Kundu KJ and Surh YJ: Inflammation: gearing the journey to cancer. Mutat Res 659: 15-30, 2008.

13. Bhatia A, Rajwanshi A, Dash RJ, Mittal BR and Saxena AK: Lymphocytic thyroiditis: is cytological grading significant? A correlation of grades with clinical, biochemical, ultrasonographic parameters. Cytojournal 4: 10, 2007.

14. Papotti M, Rodriguez J, De Pompa R, Bartolazzi A and Rosai J: Galectin-3 and HBME-1 expression in well differentiated thyroid tumors with follicular architecture of uncertain malignant potential. Mod Pathol 18: 541-546, 2005.

15. Ticconi C, Zicari A, Losardo A, Pontieri G, Pasetto N and Piccione E: Nitric oxide in human fetal membranes at term gestation: effect on prostaglandin E2 release. Eur J Obstet Gynecol Reprod Biol 69: 135-139, 1996.

16 Gupta S, Patel A, Folstad A, Fenton C, Dinauer CA, Tuttle RM, Conran R and Francis GL: Infiltration of differentiated thyroid carcinoma by proliferating lymphocytes is associated with improved disease-free survival for children and young adults. J Clin Endocrinol Metab 86: 1346-1354, 2001.

17. Tamimi DM: The association between chronic lymphocytic thyroiditis and thyroid tumors. Int J Surg Pathol 10: 10141-10146, 2002.

18. Souza SL, Montalli Da Assumpcao LV and Ward LS: Impact of previous thyroid autoimmune diseases on prognosis of patients with well-differentiated thyroid cancer. Thyroid 13: 491-495, 2003. 
19. Orucevic A, Bechberger J, Green AM, Shapiro RA, Billiar TR and Lala PK: Nitric-oxide production by murine mammary adenocarcinoma cells promotes tumor-cell invasiveness. Int J Cancer 81: 889-896, 1999.

20. Vane JR, Mitchell JA, Appleton I, Tomlinson A, BishopBailey D, Croxtall $\mathrm{J}$ and Willoughby DA: Inducible isoforms of cyclooxygenase and nitric-oxide synthase in inflammation. Proc Natl Acad Sci 91: 2046-2050, 1994.

21. Bianchi M: HMGB1 loves company. J Leukocyte Biol 86 : 573-576, 2009.
22. Mantovani A, Marchesi F, Portal C, Allavena P and Sica A: Linking inflammation reactions to cancer: novel targets for therapeutic strategies. Adv Exp Med Biol 610: 112-127, 2008

23. Sica A, Allavena P and Mantovani A: Cancer related inflammation: the macrophage connection. Cancer Lett 267: 204-215, 2008.

24. Sica A, Larghi P, Mancino A, Rubino L, Porta C, Totaro MG, Rimoldi M, Biswas SK, Allavena P and Mantovani A: Macrophage polarization in tumour progression. Semin Cancer Biol 18: 349-355, 2008. 